\title{
Meaningful Learning in Special Education Teaching and Learning Based on the Cycle of Internalized Learning: A Review
}

\author{
Shunit Reiter \\ Department of Special Education, University of Haifa, Haifa, Israel \\ Email: shunitr@edu.haifa.ac.il
}

Received 3 September 2015; accepted 15 September 2015; published 18 September 2015

\begin{abstract}
Meaningful Learning implies the active involvement of the learners/students in whatever is being taught. It is based on a holistic approach to the learners, calling for their cognitive, emotional and behavioral attention. It is also holistic in the sense that it takes into account the ecological status of the learners, their family ties; the neighborhood where they live; their formal milieu, be it a school, a social club, place of work, etc.; and their ethnic and national backgrounds. In holistic teaching the learner is perceived as a person-a subject who is undergoing development, rather than an object that is called upon to learn by rote, so that retention of information can be assessed by tests and scores. The Cycle of Internalized Learning-CIL model (Reiter, 2008) was established on the premise that individuals with disabilities were highly influenced by their environment, in the sense that there was an inseparable connection between the disability and the environment. The model addresses three levels of social behavior: the operative-what, the cultural normative-when and the moral-why. The CIL, founded on the humanistic philosophy, is relevant and applicable to people in general, and specifically to people with disabilities. Its premise states that individuals possess cognitive and rational abilities, are capable of introspection based on their understanding of their surroundings, and are capable of gaining an insight into their own motives. Thus, they are responsible for their behavior and can regulate it, by critically evaluating the outcome of their behavior and making changes, if necessary. The CIL focuses on personal progression and development. The article describes in some detail evidence-based research studies that are performed in order to further validate the CIL's contribution to student development.
\end{abstract}

\section{Keywords}

Special Education Teaching and Research, Cycle of Internalized Learning, Meaningful Learning

\section{Introduction}

The Cycle of Internalized Learning was founded on a humanistic philosophy [1]-[3]. Although it was developed specifically for students with disabilities, it can be applied to any individual or group of learners with or without 
disability. The humanistic paradigm states that all human beings possess cognitive and rational abilities, are capable of introspection and are capable of gaining insight into their own motives. Learners are thus responsible for their behavior, can regulate it and can critically evaluate the outcome of their behavior and make changes, if necessary. This implies the active involvement of learners in whatever is being learned. The application of these principles to curriculum development results in Meaningful Learning.

Meaningful Learning assumes a holistic approach to learners, calling on their cognitive, emotional and behavioral attention. It is also holistic in the sense that it takes into account the ecological status of learners, their family ties; the neighborhood where they live; their formal milieu, be it school, social club, place of work, etc.; and their ethnic and national backgrounds. A Meaningful Learning approach recognizes that the learner is an active person - a "subject" who is engaged in the process, as opposed to an "object" that is called upon to learn by rote. It recognizes that individuals with disabilities can be active learners.

Hence, this approach is implicitly inherent in the theory and practice of the Cycle of Internalized Learning (CIL) [4]. The CIL was first formulated in an action research, to evaluate a program for enhancing the autonomy of young adults with physical disabilities [5]. The program was initiated by the self-help Association of People with Physical Disabilities in the North of Israel-AHVA. The aim of the program was to prepare young adults to leave their family home and move into an independent living arrangement/facility in the community. The project included two programs run with two different groups; each program lasted 5 months. The design of the teaching model was based on a process involving the internalization of values and the circular processing of lifeevents. This process includes three components of learning: 1) the operative-what and how, 2) the cultural normative-when and where and 3) the moral—why [6].

The CIL is composed of five stages. The first stage is a presentation of a specific topic and its reference to life experiences. The second stage is comprised of academic teaching, including an analysis of the topic under study, and a clarification of definitions and generalizations. During the third stage, participants are encouraged to express their reactions to the topic and tell about their past and present emotional associations to it. Based on the personal input by the learners and the concepts learned, learners suggest alternative or new ways of behaving and problem solving. In the fourth stage the group uses role playing, simulation or practical outdoor activities to experience the alternative ways of behavior suggested by them. Finally, in the fifth stage, a discussion format is used to focus on the values that underlie individual and group behavior and to consider what each participant learned about him-or-her-self and others. Then the teacher evaluates the process outcomes, considering the extent to which students are able to apply personal and autonomous criteria of judgment in the evaluation of their life experiences and to make personal choices among alternatives. Outcomes are assessed in terms of personal autonomy, enriched knowledge and new skills.

The evaluation of the program was based on qualitative and statistical methodology. Findings of this initial evaluation of the outcomes of the program demonstrated improvement in quality of life, social competence and self-concept of participants. The teaching process was established and named the Cycle of Internalized Learning, and it became the main teaching model of the national curriculum guidelines in special education in Israel [1] [2].

The current article describes in some detail additional evidence-based research studies that were performed in order to validate CIL's contribution to student development.

\subsection{Enhancing Self Determination and Quality of Life among Students with Intellectual Developmental Disability}

The first study presented here was conducted by Pnina Shavit [7]-[9]. The focus of her study was the effect of the learning environment on enhancing self-determination and quality of life among students with intellectual developmental disability (IDD).

Shavit's research is based on the finding that school graduates with disabilities often find that being "independent" and "integrated" does not in itself ensure a better quality of life. They do not wish to merely live in a group home or community housing; rather, they desire to lead a meaningful, interesting life, with friends and freedom to make their own decisions concerning their lives [10 [11]. They want opportunities to apply personal discretion in determining their lifestyle, according to their personality and needs [3]. Nowadays, most students with intellectual disabilities who complete their schooling have limited experience in decision making and few opportunities to express their preferences. As a result, they lack initiative and self-determination, and do not function autonomously. 
The goal of the research conducted by Shavit was to compare perceptions of self-determination and of quality of life in two groups of students with IDD following two distinct types of interventional teaching programs. One group intervention was based on traditional teaching, the other on the CIL model.

Ausubel's teaching model [12] is one example of traditional teaching. It is called expository teaching and is based on the theory of information processing. According to this theory, learning is a process of absorbing, coding and storing information in our long-term memory, in a way that allows its recovery when needed. This type of learning presents the information as a whole, and is called receptive learning. The students are required to absorb the materials presented by the teacher in a way that would be useful and usable to them in the future. The activity chosen for receptive learning depends on the student's level of readiness and cognitive abilities. To achieve learning, Ausubel suggested deductive teaching [12]. Practicing this method, the teacher steers the learning process through three stages that involve the following activities: presenting a preliminary organizer, providing examples and explanations, and finally relating the details to the whole. In deductive or expository teaching, interaction during learning is basically between teacher and students, with the teacher being the authority of knowledge.

In contrast, learning based on peer group interaction is based on a process of solving problems, whereby each participant has an equal share. The teaching centers on problems that arise from personal and contextually relevant experiences, which are presented within a shared discourse. The learning process takes place while completing complex and relevant tasks that are chosen by the teacher from the realm of students' authentic life experiences. The assumption is that learning can best be achieved when students create new meanings by applying new knowledge to old problems. Shavit [8] points out that according to the CIL model, the learning process takes place within a community of learners, such that the interaction occurs among the students and between teacher and students. The teacher stimulates thinking by raising dilemmas and by encouraging students to propose possible solutions and reflect on their outcomes. The students are active participants in the discussions during the learning process. The acquisition of new knowledge, skills and values is done through group discussions and by involving the students in group learning experiences. This is unlike learning based on traditional teaching, which assumes that the teacher owns the knowledge and processes it for the students' benefit, and the interaction that takes place during the lesson is mainly between teacher and students. According to the CIL model, achievements are evaluated by outcomes such as a sense of competence, heightened motivation for further learning, self-awareness and sensitivity to others, as well as gains in knowledge and skills.

Shavit's research involved seventy-four adolescents and young adults with intellectual disabilities who participated in the study. They were divided into two groups: in one group the intervention was conducted using the traditional expository teaching approach; in the other group the intervention was taught using the CIL model. Two topics were chosen for the intervention, career and sex education. A pre-post intervention design was employed. The CIL group was further checked five months after the end of the intervention program, to check whether the learning was sustained over the long term. The research utilized both quantitative and qualitative methods. Quantitative evaluation method included the administration of several questionnaires: students completed the Self-determination Questionnaire [13] and the Quality-of-Life Questionnaire [14], and their teachers completed the Attainment of Personal Outcomes Questionnaire [15]. The qualitative evaluation method consisted of video-recorded lessons, which were used to analyze the interpersonal relationships in the two groups.

A Manova $2 \times 2$ test was applied to the statistical data. Research findings indicated that there was a significant impact of the CIL-based program on all measures of self-determination-autonomy ( $p<0.001)$, self-regulation ( $p<0.001)$ and empowerment $(p<0.001)$ and on all the measures of quality of life-satisfaction $(p<0.001)$, productive capacity $(\mathrm{p}<0.001)$ and social belonging $(\mathrm{p}<0.001)$. The impact on students who learned according to the CIL model was significantly greater than the impact on students who learned the same subjects according to the traditional expository teaching method. Furthermore, five months after the end of the program, 34 participants, 17 from each group, were contacted. Those who were not contacted had finished their schooling, moved away or had begun living in a group home. At this stage, participants completed three parts of the Self-determination Questionnaire, to evaluate autonomy, empowerment and self-regulation. Significant differences on a Manova $3 \times 2$ test were found between the groups on the three measures, such that the CIL scores were higher than in the traditional learning group. The largest differences were found in self-regulation, followed by autonomy and finally empowerment (autonomy $-\mathrm{p}<0.001$, empowerment $-\mathrm{p}<0.001$, self-regulation $-\mathrm{p}<0.001$ ). In conclusion, the changes that were found among the group participants at the end of the intervention program remained evident five months after the program's culmination. 


\subsection{Reducing Verbal Violence among Students with Intellectual Developmental Disability}

Another research study that applied the CIL as the guidelines for the intervention program was conducted by Karni [16]; its focus was on verbal violence among children with IDD. The aim of the study was to investigate verbal violence among students with IDD and the ability of a CIL-based intervention program to reduce verbal violence. For this purpose, a special education school was chosen to collaborate in the study. The major hypotheses were: 1) There will be significant gender differences in the use of verbal violence, with the girls showing a greater tendency to use verbal violence than the boys; 2) There will be a significant change in the discourse of students following the CIL program with a reduction in verbal violence.

The students in this study were recruited from a regional special education school, in which classrooms are small, consisting of 8 - 10 students. In each classroom the staff included a teacher and a teacher's aide. The total school population consisted of 80 students, who were brought in from a broad geographical area via specially arranged transportation. Most of them came from socioeconomically disadvantaged neighborhoods and many were children of new immigrants.

Forty four students were included in the study. Three classes experienced the specially-designed intervention program to reduce verbal violence $(\mathrm{N}=20)$ and two classes served as the control group $(\mathrm{N}=24)$. There were 25 girls and 19 boys between the ages of 12 and 16 (with a mean age of 14.7). The research methodology combined quantitative and qualitative measures. Test-retest procedure was applied, whereby a verbal violence questionnaire was administered to the research population (experimental and control groups) before and after the intervention program. The qualitative part of the research was based on the analyses of transcripts of several of the intervention sessions that were conducted with the experimental group.

The intervention program consisted of five lessons (50 minutes each) spread over five weeks. Due to the fact that the program was new to the teachers, they underwent a special training workshop presented by an expert on the "Cycle of Internalized Learning" model. The CIL is a group process, and it was implemented by the homeroom teacher for all of the students in the class. In each session, two variables of verbal violence were discussed. The first session was dedicated to defining and distinguishing between verbal violence and other types of violence (physical, sexual); The second session was dedicated to the variables of "insults" and "name calling"; The third session focused on "swearing" and "racial remarks"; The fourth session was on "shouting" and "humiliating"; and the last session was dedicated to "threats" and "intimidation". During the intervention program, students were encouraged to talk about their own violent behavior as well as about verbal violence expressed towards them by others and to share their experiences. They were also encouraged to suggest alternative ways of behavior.

Regarding the first hypothesis, findings indicated that although girls exhibited a greater tendency to use verbal violence, the statistical significance of the difference between boys and girls was low. As to the second hypothesis, the qualitative analysis demonstrated that the intervention program led to a process of change in verbal violence: at first, students' awareness of the phenomenon increased, which was followed by a decrease in verbal violence. Indeed, students had internalized alternative and normative ways of expressing feelings that previously had led to violence. Feelings such as anger, frustration, disappointment and the like were now controlled. For example a girl said: "Sometimes I feel like swearing and shouting, but I try not to do it anymore. Most of the time I succeed, because I remember what the teacher told me. (However) I don't always succeed... "Another student said: "I will not quarrel with her; I will not swear. It is not good. I will tell her that it is unpleasant for me...". And still another student said: "I want to get angry when I am not included. I want to shout at them, but I do not (shout). I restrain myself".

Comparisons between the experimental and the control groups revealed that students who participated in the intervention program reported a reduced tendency to engage in verbal violence (Anova repeated measures, $\mathrm{p}<$ 0.001). They learned how to identify and cope with provocative situations that might give rise to a violent response. This finding demonstrated the effectiveness of the CIL in reducing the amount of violent behavior among students with IDD.

\subsection{Career Education for Students with Intellectual Developmental Disability}

A third study that utilized the CIL model as the basis of its intervention program was conducted by Ivzori [17] [18] in the context of a Career Education and Vocational Transition Program for Students with IDD. The purpose of the study was to evaluate the effectiveness of a specially-designed career education program that uses 
the CIL model in combination with principles derived from the Model of Human Occupation [19] [20]. The intervention, which was implemented with graduate students with IDD, was intended to assess students' degree of preparedness to leave school and enter the world of remunerative work in the community. A comparison was made between the effectiveness of the traditional career education programs commonly applied in special education and the newer CIL model. The transition program was based on the five-step process of the CIL- 1 . The teacher displays an issue that was found by her to be relevant to the students' world of interests and needs in the area of employment and work, for example, "getting reprimanded at work by the boss" or "I was asked to interview for a job”; 2. Students begin to develop knowledge and concepts relating to the issue under study; 3 . Students are encouraged to make suggestions for solving problems in relation to the subject under discussion; 4. Rehearsing problem solving according to the suggestions made by the students, and 5. Reflection and feedback on the experiences with a focus on “what did I learn about myself?” and “what did I learn about others?”. Eight theoretical employability concepts were highlighted during the program: attendance at work; safety at work; work environment; worker's rights; teamwork; receiving and accepting authority; salary and initiative.

The program's effectiveness was evaluated by measuring four variables: knowledge about the world of work, understanding of concepts related to employability, self-identity as a working adult, and performance capacities in relation to the world of work. The sample, which included 77 students with IDD, was divided into a study group $(\mathrm{N}=48)$ and a control group $(\mathrm{N}=29)$. The former participated in a career education program based on the CIL principles and the latter participated in a career education program traditionally used in special education. The intervention program was implemented throughout most of the school year, over a period of eight months, and involved several outings to places of work, as well as a trial work experience, in which students were placed individually to work at a job outside of school for a few days. A combined qualitative and quantitative methodology was employed; hence, data collection required the use of several channels, namely, questionnaires, interviews and focus groups. Pre- and post-assessments were administered at the beginning and at the end of the program, respectively. In addition, three interviews were conducted with every program participant, and two focus groups were held, one during the course of the program and one at the end. Comparison of the findings gathered at the beginning and at the end of the program by applying Anova test for repeated measures showed that the students in the research group improved significantly $(p<0.001)$ in comparison with the control group on the variables of knowledge about the world of work, their level of understanding of concepts related to employability, and their work-related capacities. In addition, findings indicated a meaningful development of their self-identity as productive adults $(\mathrm{p}<0.05)$.

\subsection{Enhancing Self Awareness and Self Esteem among Students with Visual Impairments: A Focus on Empowerment and Quality of Life}

The three studies, by Shavit, Karni-Vizer and Yonat, demonstrated the effectiveness of the CIL model with a population of students with IDD. Research done by Hess [21] demonstrated the contribution of the CIL model in the context of a different population, that of students with visual impairments (VI) and blindness. Hess conducted two research investigations as part of his post-doctoral studies at the University of Haifa; both studies were funded by a grant from the Israel Science Foundation. One study involved school-age students and was titled Improving Self-Awareness and Self-Esteem as a Step towards Developing Self-determination among Students with Visual Impairments and Blindness; the other, which examined the model with a different age group, was titled An Educational-Humanistic Model Applied with University and College Students with Visual Impairments: A Focus on Empowerment and Quality of Life.

The first research was with school-age students. In Israel all students with VI are integrated in general education. However, there is one residential school for students with VI, which caters to students with VI who come from underprivileged socioeconomic backgrounds and demonstrate low academic achievements in general education schools. This residential school's main objective is to empower students on an individual level, so that they can return to their home community after a year or two and be successfully re-integrated in the general education schools. A critical stage in the process of their empowerment involves the development of a realistic awareness of the way they cope with their disability, which is complemented by the enhancement of self-esteem. For this reason, the main goal of the program was defined as helping students develop a positive and appropriate attitude regarding their abilities as well as about visual impairment or blindness. From a total of 34 students enrolled in the school, a sample of 29 students was chosen by the school principal to participate in the research. 
They were divided into five groups, according to academic ability. Each group was led by one homeroom teacher who conducted the intervention program. Before the initiation of the intervention program, all teachers underwent a special in-service training on the principles and implementation of the CIL model. Two main themes were explored in the course of the intervention program. The first was the development of a heightened level of self-awareness. To this end, students were required to explore the physiological side of the disability, by undergoing medical examinations, learning about the functional consequences of the disability, being informed of opportunities to receive treatment, and being exposed to state-of-the-art vision aids and pain relief treatments. The second theme was life in school, which was intended to give students insight into personal capabilities and challenges. To this end, students learned of ways to cope with tests and grades and considered methods for coping with stigma and improving social and interpersonal relationships.

A pre-post research design was applied, together with a qualitative evaluation based on a focus group conducted with the participating homeroom teachers at the end of the program. Two types of questionnaires were used: one was intended for students to report on their attitudes regarding their impairment, their coping with the impairment, and their self-esteem. The second type of questionnaire was intended for the teachers. They were asked to complete a questionnaire regarding each student, reporting on 1) the student's ability to cope on one's own (by assessing the student's rate of productivity, activity, and flexibility in activities); 2) the student's ability to cope with the environment (by assessing the same variables). The program lasted 6 months and was implemented in the course of a single school year.

The major finding of the study was that participation in the program led students to form a new perception of the effect of VI on their lives. Following the program, participating students considered their visual impairment to be less of a threat to and have less of an effect on their way of life than they did before the program (t-test for small samples, $\mathrm{p}<0.05)$.

Apparently, participating students developed a more realistic perception of themselves and their relationships with others at the end of the program. This was substantiated by yet another significant finding, namely, that after the program there was a higher percentage of agreement between teachers' assessments of their students and the students' self-assessments, in regard to several quality-of-life components (Spearman rank order correlations $-r=0.48, p<0.05$ ). This finding suggests that the intervention program also led to improved interpersonal relationships between teachers and students.

Moreover, findings from the teachers' focus group, conducted towards the end of the program, confirmed the conclusion that there were improvements in numerous components of students' quality of life, as the following excerpts demonstrate. "The program helped resolve conflicts and arguments between pupils, as when one child attempts to impose his or her view on the others. There’s been a noticeable change since the program began.” "The work on dealing with stigmas was truly comprehensive. Our discussion of stigmas among students raised the issue of stigmas in the family, something that had never been discussed before the program was implemented."

Hess's second study applying the CIL model was conducted with higher-education students attending university and college courses [22]. Obviously, the main issues of adult students' daily lives differ from those of school children, as they include work, civic status, and intimate relationships between couples, to mention but a few. However, the assumption underlying the program for young-adult students with VI was identical to that which guided the intervention program for the younger students. This assumption is derived from the educational-humanistic worldview and claims that as students become more realistically informed regarding their visual impairment and its effect on their lives and as they internalize this knowledge; their ability to function independently and to be more autonomous in their decision making will improve. This in turn will result in a more successful adaption to their various environments, i.e., family, school, and community. The ability to adapt in this sense will significantly empower them and improve their quality of life. For this reason, the content areas of the program were adjusted to address issues that students of higher education encounter, such as studying in an academic framework (which is different from their experience of learning at school), work, intimate relationships, and the community. As in all programs based on CIL, here too there was an ongoing effort to ensure that students constantly internalized newly acquired information.

A group of nine students expressed an interest in joining 12 meetings of a focus group on the issue of coping as a blind student on campus. The methodology employed was qualitative: every participant was asked to write a diary after each meeting. Participants were asked to refer in their writings to the various dimensions of the CIL model, i.e., the issue under discussion, information and concepts related to the issue; suggestions for alternative 
ways to solve problems related to the issue; their experiences trying out new coping behaviors; insights and conclusions regarding "myself and others". At the same time, the content of the entries was not limited to the aforementioned guidelines, and no guidance was given in terms of the structure of entries in the journal. Also the researcher who conducted the group meetings kept a diary reflecting his ideas, conclusions and thoughts after each meeting, and his journal too was used in the final analyses.

In addition, before and after the program's implementation, participants were asked to complete a questionnaire (the same one that had been administered to school-age students) regarding their emotional and cognitive coping with the impairment.

The major finding of the study was that, in general, participants reported that the intervention had contributed to an improved understanding of various aspects of their lives; more specifically, it alerted them to the need to cope with their impairment in various spheres concurrently, for example the medical and legal spheres, and their social and family spheres. The program changed the ways in which they coped with the impairment and its implications. As participants became more aware of various options, they felt increased personal motivation to address the issues related to the effects of VI on their everyday lives, they expressed an increased interest in some of the issues raised in the program and a greater willingness to investigate these issues, as well as others that were beyond the scope of the study. As one participant observed: "clearly the Internalization Cycle (the CIL) made me view reality with slightly more optimism". The journal reports indicated that participants felt empowered. The issue of coping with personal and social stigmas was raised repeatedly, and it appears that the discussion and deliberation on the topic, as well as the individual and group ideas that were raised about coping with the issue, took a central place in the program.

In conclusion, participants in both studies, i.e., school-aged students as well as higher-education students reported that their perception of their visual impairment was less negative than it had been before the program. The impairment became less threatening and its effect on their lives was less limiting than it had been before the program. Furthermore, at the end of the two programs, participants reported on their self-esteem in a more balanced manner than they had done before the intervention, when they had used extreme expressions. More specifically, in the first session of the program, participants, regardless of age group, either ignored the disability or was constantly preoccupied with its harmful effect, most noticeably their sense of social rejection. At the end of the program, both school-aged and college-aged participants showed the budding signs of more positive selfesteem.

\subsection{An Organizational Model of Inclusion between a Regular and a Special School: A Focus on a Combined, Special and Regular Pedagogical Method}

The CIL model was also applied with regular and special-education school students involved in an inclusive program. The aim of the program was to develop a novel model of integration and inclusion between two schools, a special education and a regular education school [23]. The program was funded (1999-2014) by the Department of Experiments and Initiatives of the Ministry of Education, Jerusalem, Israel and was followed by action research. The aim of the program was to develop an organizational and pedagogical model of inclusion, which would be used in forging a link between two separate schools. The project in general aimed to demonstrate the feasibility of maintaining ongoing inclusion activities that form part of teachers' and students' daily routines. This was done by means of joint collaboration and sharing of activities of learning and enrichment. One sphere of collaboration pertained to joint planning of and participation in holiday ceremonies, parties, or a day dedicated to sports events, for example, as well as forming a combined student committee for leading environmental design projects, in school and in the community. Apart from these collaborative efforts, the two schools run a weekly program of extracurricular classes, such as sports, cooking, dancing, choir, film-making, computer classes, and jewelry making, which are attended jointly by students from both schools, thus providing a framework in which they can meet and interact. Teachers from both schools run the program and the activities are held either in one or the other school. These joint activities are followed by discussions held within the homeroom class, during which the teacher asks the students to bring up issues related to interpersonal relationships among students, misunderstandings, and disappointments. The teachers in both schools also give students their feedback concerning difficulties in communication between the regular students and the students with special needs. In order to conduct effective follow-up discussions, a new pedagogical program was designed, based on the CIL and in line with the regular school curriculum unit on social values, called "the key to the heart". The 
latter is a social education program designed to enhance social competencies for meaningful interpersonal relationships based on norms and values such as respect for the other, listening, problem solving, and community involvement. Teachers and students in both schools bring up issues that happened during the shared activity, according to the stages suggested by the CIL model, i.e., starting with an event, learning concepts and gaining new knowledge concerning the event, followed by analyzing it using the concepts and data learned, expressing personal insights, and suggesting alternative ways of responding to the event. Over the five years of the field experiment, an organizational culture of inclusion was created, which allowed each school to keep its unique identity, while at the same time sharing its vision of inclusion by conducting joint activities.

\section{Conclusion}

In summary, the research studies described in this paper, in which the CIL model was applied as the basis for intervention programs, demonstrate its applicability with diverse populations and diverse content areas, as well as with groups of various ages. Most studies evaluated the effectiveness of the model using a mixed statistical and qualitative methodology. Regardless of the assessment methodology employed, findings indicated that the effectiveness of the CIL model and its contribution to students' development was significant. Meaningful learning was not only found to be feasible with diverse populations with special needs, but also applicable and effective for use with students without special needs. In both cases, it was found to contribute to a significant improvement in their quality of life.

\section{References}

[1] Reiter, S. (2000) Quality of Life: A Central Theme of the New High-school Curriculum Guidelines for Teachers of Adolescents with Developmental Disabilities, A national Project, Israel. International Journal of Adolescent Medicine and Health, 12, 19-32.

[2] Reiter, S. and Schalock, R.L. (2008) Applying the Concept of Quality of Life to Israeli Special Education Programs: A National Curriculum for Enhanced Autonomy in Students with Special Needs. International Journal of Rehabilitation Research, 31, 13-21. http://dx.doi.org/10.1097/MRR.0b013e3282f45201

[3] Reiter, S. (2008) Disability from a Humanistic Perspective: Towards a Better Quality of Life. Nova Science Publishers Book Series: Health and Human Development, New York.

[4] Reiter, S. (1999) Conclusions: Cross-Cultural Perspectives-Diversity and Universalism. In: Retish, P. and Reiter, S., Eds., Adults with Disabilities: International Perspectives in the Community, Lawrence Erlbaum Associates Publishers, New Jersey, 325-337.

[5] Reiter, S. and Goldman, T. (1999) A Programme for the Enhancement of Autonomy in Young Adults with Physical Disabilities: The Development of a Realistic Self-Concept, Individual Perception of Quality of Life and the Development of Independent Living Skills. International Journal of Rehabilitation Research, 22, 71-74. http://dx.doi.org/10.1097/00004356-199903000-00011

[6] Reiter, S. and Bryen, D. (1991) Promoting Social Competence: Implications of Work with Mentally Retarded Children and Adults in Residential Setting. In: Beker, J. and Eisikovits, Z., Eds., Knowledge Utilization in Residential Child and Youth Care Practice, Child Welfare League of America, Washington DC, 99-123.

[7] Shavit, P. (2008) The Enhancement of Self-Determination of Students With Intellectual Disabilities Involved in a Group Process Based on The “Cycle of Internalization”. Ph.D. Thesis, University of Haifa, Haifa.

[8] Shavit, P. (2010) Towards Inclusion, Enhancing Self-Determination in Students with Intellectual Disabilities by Means of Group Interaction. Proceedings of the International Conference on Inclusive and Supportive Education: Promoting Diversity and Inclusive Practice ISEC, Queen's University of Belfast, Ireland, 1-5 August 2010.

[9] Shavit, P. (2013) Enhancing Meta-Cognitive Thinking of Students with Intellectual Disabilities: Presenting the Cycle of Internalized Learning (CIL). Proceedings of The Annual Conference, Education for the Future, Ostfold University, Halden College, Norway, 22-25 August 2013.

[10] Longmore, P. (2003) Why I Burned My Book and Other Essays on Disability. Temple University Press, Philadelphia.

[11] Michalko, R. (2002) The Difference That a Disability Makes. Temple University Press, Philadelphia.

[12] Ausubel, D. (1968) The Psychology of Meaningful Verbal Learning: An Introduction to School Learning. Grune \& Stratton, New York.

[13] Wehmeyer, M.L. and Kelchner (1995) The Arc's Self-Determination Scale. The ARC of the United States, Arlington.

[14] Schalock, R. and Keith, K.D. (1993) Quality of Life Questionnaire Manual. Intellectual Developmental Disabilities 
Publication Corporation, Washington DC.

[15] Gardner, J.F. and Carran, D. T. (2005) Attainment of Personal Outcomes by People with Developmental Disabilities. Mental Retardation, 43, 157-174. http://dx.doi.org/10.1352/0047-6765(2005)43[157:AOPOBP]2.0.CO;2

[16] Karni-Vizer, N. (2014) Effectiveness of an Intervention Program on Verbal Violence among Students with Intellectual Disabilities. International Journal of Secondary Education, 3, 1-7.

[17] Ivzori, Y. (2010) Career, Education and Vocational Transition Program: Preparation for a Working Life for Students with Intellectual Disabilities. Ph.D. Thesis, University of Haifa, Haifa.

[18] Ivzori, Y., Reiter, S. and Sachs, D. (2011) Model of Human Occupation and Constructivist Learning: A Theoretical and Practical Basis for Developing a Transition Program for Preparation for a Working Life. Israeli Journal of Occupational Therapy, 20, H145-H172 (Hebrew, English Abstract).

[19] Kielhofner, G. (2002) Dimensions of Doing. In: Kielhofner, G., Ed., Model of Human Occupation: Theory and Application (3rd Edition,) Lippincott Williams \& Wilkins, Philadelphia, 101-109.

[20] Kielhofner, G. (2004) Conceptual Foundation of Occupational Therapy. 3rd Edition, F.A. Davis Company, Philadelphia, 147-170.

[21] Reiter, S. and Hess, I. (2010) Students with Visual Impairments and the Humanistic Paradigm: Personality Variables, Self-determination and Self-advocacy-A Comprehensive Model of Quality of Life. Report No. 950/08. University of Haifa, Haifa, ISF - Israel Science Foundation, Israel.

[22] Hess, I. (2014) An Educational-Humanistic Model for Empowerment the Quality of Life of Students with Visual Impairments. Proceedings of the International Conference on Higher education, Tel Aviv, 16-18 March 2014.

[23] Reiter, S., Ram, D. and Dramer, I. (in Press) A Novel Model of Integration and Inclusion Between Two Schools, Special Education, the Szold School and Regular Education, the Yavniali School. Special Education and Inclusion. (Hebrew, English Abstract). 